\title{
Risk Factors for Behavioral Abnormalities in Mild Cognitive Impairment and Mild Alzheimer's Disease
}

\author{
Liana G. Apostolova ${ }^{a} \quad$ Li Jie Di $^{a} \quad$ Erin L. Duffy ${ }^{b}$ Jenny Brook ${ }^{b}$ \\ David Elashoff $^{b}$ Chi-Hong Tseng ${ }^{b}$ Lynn Fairbanks ${ }^{c}$ \\ Jeffrey L. Cummings ${ }^{d}$
}

Departments of a Neurology, ${ }^{b}$ Medicine Statistics Core and ${ }^{\mathrm{c} P s y c h i a t r y}$ and Biobehavioral Sciences, UCLA, Los Angeles, Calif., and d Lou Ruvo Center for Brain Health, Cleveland Clinic, Las Vegas, Nev., USA

\section{Key Words}

Neuropsychiatric symptoms · Behavior - Mild cognitive impairment - Alzheimer's disease

\begin{abstract}
Background: Behavioral symptoms are common in both mild cognitive impairment (MCI) and Alzheimer's disease (AD). Methods: We analyzed the Neuropsychiatric Inventory Questionnaire data of 3,456 MCI and 2,641 mild AD National Alzheimer's Coordinating Center database participants. Using factor analysis and logistic regression we estimated the effects of age, sex, race, education, Mini-Mental State Examination, functional impairment, marital status and family history on the presence of behavioral symptoms. We also compared the observed prevalence of behavioral symptoms between amnestic and nonamnestic MCI. Results: Four factors were identified: affective behaviors (depression, apathy and anxiety); distress/tension behaviors (irritability and agitation); impulse control behaviors (disinhibition, elation and aberrant motor behavior), and psychotic behaviors (delusions and hallucinations). Male gender was significantly associated with all factors. Younger age was associated with a higher prevalence of distress/tension, impulse control and psychotic behaviors. Being married was protective against psychotic behaviors. Lower education was associated with the presence of distress/tension behaviors. Caucasians showed a higher prevalence of affective behaviors. Functional impairment was strongly associated with all behavioral abnormalities. Amnestic MCI patients had more elation and agitation relative to nonamnestic MCI patients. Conclusions: Younger age, male gender and greater functional impairment were associated with higher overall presence of behavioral abnormalities in MCI and mild AD. Marital status, lower education and race had an effect on selected behaviors.


Apostolova et al.: Risk Factors for Behavioral Abnormalities in Mild Cognitive

Impairment and Mild Alzheimer's Disease

Neuropsychiatric symptoms are exceedingly prevalent in Alzheimer's disease (AD). They affect $42 \%$ of those with mild, $80 \%$ with moderate, and over $90 \%$ with advanced AD [1]. In the mild cognitive impairment (MCI) stage, $35-75 \%$ of patients experience at least one neuropsychiatric symptom [2]. Neuropsychiatric disturbances are major contributors to the emotional, social and economic burden of dementia and are the leading cause for hospitalization, residential placement, and psychopharmacologic therapy [3-6].

The most established risk factor for behavioral symptoms is disease severity [2]. Older age has been linked to lower prevalence of anxiety [7], increased prevalence of psychosis [8, 9] and aberrant motor behaviors [9]. Some researchers have linked higher education in AD to lower [10-12] and others to higher [13] prevalence of depression and psychosis. Other studies have reported lack of association $[14,15]$. Family history of dementia has been linked to the presence of anxiety, irritability [16] and psychosis [16,17]. Female AD subjects have a higher prevalence of anxiety relative to male AD subjects [7].

The risk/protective factors for the manifestation of behavioral symptoms in MCI and mild AD have not been thoroughly researched to date. Here we report in-depth analyses of the risk factors associated with prevalence of neuropsychiatric features among MCI and mild AD National Alzheimer's Coordinating Center (NACC) database participants.

\section{Methods}

Subjects

We used demographic, cognitive and neuropsychiatric data of 3,456 MCI and 2,641 mild AD subjects from the NACC. The NACC resource (NIA U01 AG016976) was established in 1999 and contains data from 34 past and present NIA-funded Alzheimer's Disease Centers across the United States. NACC data are freely available to all researchers. Qualifying subjects were required to be 50-100 years old, have a diagnosis of AD or MCI made according to standard research criteria [18, 19], Neuropsychiatric Inventory (NPI) questionnaire data, Mini-Mental State Examination (MMSE) score $>20$ and no other neurological or psychiatric diagnoses. We limited our analyses to subjects included in the Alzheimer's Disease Centers' Uniform Data Set between September 2005 and August 2011. AD subjects were additionally required to have a global Cognitive Dementia Rating scale score $<2$. As this is a study of preexisting data from a national repository provided to the principal investigator without any personal identifying information, the analyses reported here are exempt from Institutional Review Board approval. The exemption status has been confirmed with the UCLA Institutional Review Board.

\section{Variable Construction}

NACC variables included clinical diagnosis, age, sex, race, education, MMSE, Functional Activity Questionnaire (FAQ) scores, marital status, parental history of dementia and second-degree relative history of dementia. Age, MMSE and FAQ were used as continuous variables. All FAQ entries 'not applicable/never did' were coded as missing data. Education was categorized as $<6,6-12$ and $>12$ years of education except in the multivariable regression analyses where it was used as a continuous variable for ease of interpretation of odds ratios. The effects of race were studied by constructing dummy variables of African American and Asian relative to Caucasian race. Gender, marital status (married vs. not married), parental and second-degree relative history of dementia were entered as binary variables. The 'not married' category included 'never married', 'widowed', 'divorced' and 'separated'.

\section{Statistical Analyses}

We used two-tailed t tests for continuous and $\chi^{2}$ statistics for categorical variables to compare the demographic, cognitive and neuropsychiatric characteristics of subjects with $\mathrm{MCI}$ versus mild $\mathrm{AD}$ and amnestic MCI versus nonamnestic MCI.

We used principal component factor analysis with varimax rotation to examine the joint variation and interdependencies among the 10 NPI variables in the pooled sample. The factor analysis was conducted using the pooled sample of MCI and mild AD subjects for whom all predictor variables were available $(n=4,874)$. Four factors were identified and factor scores were computed for each factor, incorporating the 10 NPI vari- 
Apostolova et al.: Risk Factors for Behavioral Abnormalities in Mild Cognitive Impairment and Mild Alzheimer's Disease

ables in all of the factor scores. Linear regression analyses were conducted to assess the association between the scores of the 4 factors and the predictor variables age, sex, education, race, marital status, parental and second-degree relative history of dementia, MMSE and FAQ.

The following analyses were conducted separately in the mild AD, MCI and pooled samples. We first studied the univariate associations between the presence or absence of neuropsychiatric behaviors and our predictor variables - age, sex, education, race, marital status, parental and second-degree relative history of dementia, MMSE and FAQ - using $\chi^{2}$ statistics for categorical variables and univariate logistic regression for continuous variables. Next, we conducted multivariable logistic regression to study the adjusted effects of all predictor variables on each neuropsychiatric feature and behavioral factor, respectively, using age, sex, education, race, marital status, parental and second-degree relative history of dementia, MMSE and FAQ as predictor variables.

We compared the prevalence of neuropsychiatric symptoms between amnestic and nonamnestic $\mathrm{MCl}$ using $\chi^{2}$ statistics. Univariate $\chi^{2}$ and t test analyses were conducted to compare age, sex, education, race, marital status, parental and second-degree relative history of dementia, MMSE and FAQ between amnestic and nonamnestic MCI subjects. Multivariate logistic models were developed to predict the neuropsychiatric symptoms that were found to be significantly different between the amnestic and nonamnestic MCI subjects. Predictor variables that were significantly different between amnestic and nonamnestic MCI subjects in univariate analyses were included in these multivariate logistic models.

\section{Results}

\section{Demographic Characteristics of the Study Population}

The mild AD group was significantly older, less educated, and more cognitively and functionally impaired relative to the MCI group (table 1). Mild AD subjects had a significantly greater proportion of Caucasians, and were less likely to be married or have a parental history of dementia relative to MCI subjects (table 1).

2,837 MCI participants met criteria for the amnestic and 619 for the nonamnestic subtype. Amnestic MCI subjects were significantly older (75.6 \pm 8.7 vs. $74.1 \pm 8.7$ years, $p<0.0001)$, more cognitively (MMSE score $27 \pm 2.3$ vs. $27.6 \pm 2.1, \mathrm{p}<0.0001$ ) and functionally impaired (FAQ score $3.5 \pm 4.6$ vs. $2.6 \pm 4.2, \mathrm{p}<0.0001$ ), and more educated ( $\mathrm{p}=0.001$ ) compared to nonamnestic MCI subjects, but had comparable marital status, and parental or second-degree relative history of dementia. There was a significantly higher proportion of men among amnestic versus nonamnestic MCI subjects (47 vs. $41.5 \%, \mathrm{p}=0.0093$ ).

All neuropsychiatric behaviors except depression were significantly more common in mild AD versus MCI. MCI subtypes differed only in the prevalence of agitation and elation both were more common among amnestic MCI (table 2).

\section{Factor Analyses}

We identified 4 separate factors both in the full sample and in the sample restricted to only those subjects with all predictor variables available (table 3). Affective behaviors depression, anxiety and apathy - had the strongest loadings on factor 1 . Distress/tension behaviors such as agitation and irritability strongly loaded on factor 2. Impulse control behaviors such as disinhibition, elation and aberrant motor behavior loaded on factor 3 . Psychotic behaviors - delusions and hallucinations - loaded on factor 4. These factor loadings were evaluated and determined to represent four behavior groups: (1) affective behaviors, (2) distress/tension behaviors, (3) impulse control behaviors, and (4) psychotic behaviors.

\section{Factor Linear Regression Analyses}

Factor 1 (affective disorders: depression, anxiety and apathy) was negatively associated with age $(\mathrm{p}<0.0001)$, Asian $(\mathrm{p}<0.0001)$ and African American race $(\mathrm{p}<0.0001)$ and positively 
Table 1. Demographic characteristics

\begin{tabular}{|c|c|c|c|c|}
\hline Categories & $\begin{array}{l}\text { Pooled sample } \\
(n=6,097)\end{array}$ & $\begin{array}{l}\text { MCI } \\
(n=3,456)\end{array}$ & $\begin{array}{l}\text { Mild AD } \\
(n=2,641)\end{array}$ & $\begin{array}{l}\mathrm{p} \text { value (mild } \\
\text { AD vs. } \mathrm{MCI} \text { ) }\end{array}$ \\
\hline Age, years & $75.7 \pm 8.7$ & $75.4 \pm 8.7$ & $76.0 \pm 8.8$ & 0.0034 \\
\hline \multicolumn{4}{|l|}{ Gender } & \multirow[t]{3}{*}{0.30} \\
\hline Male & $2,784(46)$ & $1,598(46)$ & $1,186(45)$ & \\
\hline Female & $3,313(54)$ & $1,858(54)$ & $1,455(55)$ & \\
\hline \multicolumn{4}{|l|}{ Education } & \multirow[t]{4}{*}{$<0.0009$} \\
\hline$<12$ years & $561(9)$ & $327(9)$ & $234(9)$ & \\
\hline $12-16$ years & $3,834(63)$ & $2,105(61)$ & $1,729(65)$ & \\
\hline$>16$ years & $1,702(28)$ & $1,024(30)$ & $678(26)$ & \\
\hline \multicolumn{4}{|l|}{ Race } & \multirow[t]{5}{*}{$<0.0001$} \\
\hline White & $4,960(81)$ & $2,706(78)$ & $2,254(85)$ & \\
\hline African American & $825(14)$ & $559(16)$ & $266(10)$ & \\
\hline Asian & $117(2)$ & $79(2)$ & $38(1)$ & \\
\hline Other & $195(3)$ & $112(3)$ & $83(3)$ & \\
\hline \multicolumn{4}{|l|}{ Married } & \multirow[t]{3}{*}{$<0.0001$} \\
\hline Yes & $3,876(63)$ & $2,101(61)$ & $1,775(66)$ & \\
\hline No & $2,221(37)$ & $1,355(39)$ & $866(34)$ & \\
\hline \multicolumn{4}{|c|}{ Parental history of dementia } & \multirow[t]{5}{*}{0.017} \\
\hline Yes & $2,814(52)$ & $1,555(45)$ & $1,259(48)$ & \\
\hline No & $3,165(46)$ & $1,844(54)$ & $1,321(50)$ & \\
\hline Unknown & $91(2)$ & $44(1)$ & $48(2)$ & \\
\hline Missing & $27(<0.5)$ & $13(<0.5)$ & $14(<0.5)$ & \\
\hline \multicolumn{4}{|c|}{ Second-degree relative history of dementia } & \multirow[t]{5}{*}{0.142} \\
\hline Yes & $1,486(24)$ & $871(25)$ & $615(23)$ & \\
\hline No & $3,424(56)$ & $1,936(56)$ & $1,488(57)$ & \\
\hline Unknown & $1,160(19)$ & $636(19)$ & $524(20)$ & \\
\hline Missing & $27(<0.5)$ & $13(<0.5)$ & $14(<0.5)$ & \\
\hline MMSE score & $25.7 \pm 2.9$ & $27.1 \pm 2.3$ & $23.9 \pm 2.6$ & $<0.0001$ \\
\hline FAQ score & $7.1 \pm 7.2$ & $3.3 \pm 4.5$ & $12.0 \pm 7.2$ & $<0.0001$ \\
\hline
\end{tabular}

Figures are mean \pm SD or $n(\%)$. $p$ values in bold indicate significance.

Table 2. Frequency of NPI symptoms

\begin{tabular}{|c|c|c|c|c|c|c|c|}
\hline NPI variable & $\begin{array}{l}\text { Pooled } \\
\text { sample } \\
(n=6,097)\end{array}$ & $\begin{array}{l}\text { MCI } \\
(n=3,456)\end{array}$ & $\begin{array}{l}\text { Mild AD } \\
(\mathrm{n}=2,641)\end{array}$ & $\begin{array}{l}\text { p value } \\
\text { (mild AD } \\
\text { vs. MCI) }\end{array}$ & $\begin{array}{l}\text { Amnestic } \\
\text { MCI } \\
(\mathrm{n}=2,837)\end{array}$ & $\begin{array}{l}\text { Nonam- } \\
\text { nestic MCI } \\
(\mathrm{n}=619)\end{array}$ & $\begin{array}{l}\mathrm{p} \text { value } \\
\text { (amnestic vs. } \\
\text { nonamnestic MCI) }\end{array}$ \\
\hline Delusions & $428(7)$ & $122(4)$ & $306(12)$ & $<0.0001$ & $97(3)$ & $25(4)$ & 0.5 \\
\hline Hallucinations & $117(2)$ & 34 (1) & $83(3)$ & $<0.0001$ & $27(1)$ & $7(1)$ & 0.7 \\
\hline Depression & $1,116(18)$ & 669 (19) & 447 (17) & $<0.015$ & $553(20)$ & $116(19)$ & 0.7 \\
\hline Apathy & $1,624(27)$ & $627(18)$ & $997(38)$ & $<0.0001$ & $520(18)$ & 107 (17) & 0.5 \\
\hline Anxiety & $1,579(25)$ & 705 (20) & $825(31)$ & $<0.0001$ & $585(21)$ & $120(19)$ & 0.5 \\
\hline Irritability & $1,891(31)$ & $908(26)$ & $983(37)$ & $<0.0001$ & $749(26)$ & $159(26)$ & 0.7 \\
\hline Agitation & $1,340(22)$ & $562(16)$ & $778(30)$ & $<0.0001$ & $479(17)$ & $83(13)$ & 0.034 \\
\hline Disinhibition & $707(12)$ & $274(8)$ & $433(16)$ & $<0.0001$ & $218(8)$ & $56(9)$ & 0.3 \\
\hline Elation & $148(2)$ & $56(2)$ & $92(3)$ & $<0.0001$ & $52(2)$ & $4(1)$ & 0.034 \\
\hline \multicolumn{8}{|l|}{ Aberrant motor } \\
\hline behavior & $482(8)$ & $149(4)$ & $333(13)$ & $<0.0001$ & $117(4)$ & $32(5)$ & 0.2 \\
\hline
\end{tabular}

Figures in parentheses indicate percentages. p values in bold indicate significance. 
Apostolova et al.: Risk Factors for Behavioral Abnormalities in Mild Cognitive Impairment and Mild Alzheimer's Disease

Table 3. Factor loadings based on a principle components analysis with varimax rotation for ten NPI variables

\begin{tabular}{lllll}
\hline NPI variables & $\begin{array}{l}\text { Affective } \\
\text { behaviors }\end{array}$ & $\begin{array}{l}\text { Distress/tension } \\
\text { behaviors }\end{array}$ & $\begin{array}{l}\text { Impulse control } \\
\text { behaviors }\end{array}$ & $\begin{array}{l}\text { Psychotic } \\
\text { behaviors }\end{array}$ \\
\hline Depression & $\mathbf{0 . 4 7}$ & 0.15 & 0.05 & 0.09 \\
Anxiety & $\mathbf{0 . 4 3}$ & 0.13 & 0.14 & 0.11 \\
Apathy & $\mathbf{0 . 3 8}$ & 0.18 & 0.15 & 0.10 \\
Agitation & 0.24 & $\mathbf{0 . 5 0}$ & 0.22 & 0.14 \\
Irritability & 0.30 & $\mathbf{0 . 4 9}$ & 0.17 & 0.08 \\
Disinhibition & 0.17 & 0.25 & $\mathbf{0 . 3 4}$ & 0.17 \\
Elation & 0.06 & 0.08 & $\mathbf{0 . 2 6}$ & 0.10 \\
Aberrant motor behavior & 0.22 & 0.10 & $\mathbf{0 . 2 2}$ & 0.13 \\
Delusions & 0.13 & 0.19 & 0.19 & $\mathbf{0 . 2 8}$ \\
Hallucinations & 0.06 & 0.03 & 0.08 & $\mathbf{0 . 2 5}$ \\
\hline
\end{tabular}

associated with FAQ ( $\mathrm{p}<0.0001)$. Factor 2 (distress/tension disorders: irritability and agitation) was negatively associated with age $(\mathrm{p}<0.0001)$ and education $(\mathrm{p}=0.0298)$, and positively associated with male gender $(\mathrm{p}<0.0001)$, MMSE $(\mathrm{p}<0.0001)$ and FAQ $(\mathrm{p}<0.0001)$. Factor 3 (impulse control disorders: disinhibition, elation and aberrant motor behaviors) showed negative association with age $(\mathrm{p}<0.0001)$ and positive association with male gender $(\mathrm{p}<0.0001)$, MMSE $(\mathrm{p}=0.0093)$ and FAQ $(\mathrm{p}<0.0001)$. Factor 4 (psychotic disorders: delusions and hallucinations) showed negative association with age $(p=0.0018)$ and being married $(p=0.0021)$ and positive association with male gender $(p=0.0444)$ and FAQ $(p<0.0001)$.

\section{Univariate Analyses}

Significance results from the univariate analyses are presented in table 4. Younger age was associated with the presence of depression, anxiety and irritability across all samples, as well as elation in the MCI and pooled samples, delusions in the pooled and apathy in the AD sample only.

Female sex was associated with a higher prevalence of depression but lower prevalence of apathy, agitation, irritability and disinhibition in all 3 samples. Women also showed a significantly lower frequency of elation in the pooled and MCI samples and a higher prevalence of anxiety in the pooled sample. Women had a higher prevalence of delusions in the mild $\mathrm{AD}$ and pooled samples.

Lower education was associated with a higher prevalence of delusions and depression in all three samples (pooled, MCI only and AD only), a higher prevalence of hallucinations in the $\mathrm{MCI}$ and pooled samples, a higher prevalence of agitation in the mild $\mathrm{AD}$ and pooled samples, and a lower prevalence of apathy in the mild AD sample.

Being married was associated with a higher prevalence of apathy and irritability and a lower prevalence of depression and delusions in all three samples, a higher prevalence of agitation in the $\mathrm{MCI}$ and pooled sample, a higher prevalence of anxiety in the pooled sample, and a lower prevalence of hallucinations in the mild AD sample.

Parental history of dementia was associated with a higher frequency of irritability in the MCI and pooled sample, a higher prevalence of delusions and disinhibition in the pooled sample and a higher prevalence of depression and delusions in mild AD.

Second-degree relative history of dementia was associated with a greater prevalence of hallucinations, disinhibition and aberrant motor behaviors in mild AD and the pooled sample and a greater prevalence of anxiety and apathy in mild AD. 
Apostolova et al.: Risk Factors for Behavioral Abnormalities in Mild Cognitive Impairment and Mild Alzheimer's Disease

Table 4. Univariate $\chi^{2}$ and logistic regression analyses ( $p$ values)

\begin{tabular}{|c|c|c|c|c|c|c|c|c|c|c|}
\hline Sample & DEL & HAL & DEP & APA & ANX & IRR & AGIT & DISN & ELAT & MOT \\
\hline \multicolumn{11}{|l|}{ Age } \\
\hline Pooled & 0.02 & 0.36 & $<0.0001$ & 0.15 & $<0.0001$ & $<0.0001$ & 0.28 & 0.75 & 0.03 & 0.31 \\
\hline MCI & 0.14 & 0.44 & $<0.0001$ & 0.43 & $<0.0001$ & $<0.0001$ & 0.28 & 0.55 & 0.0046 & 0.087 \\
\hline $\mathrm{AD}$ & 0.16 & 0.19 & 0.03 & 0.03 & $<0.0001$ & $<0.0001$ & 0.26 & 0.16 & 0.41 & 0.54 \\
\hline \multicolumn{11}{|l|}{ Sex } \\
\hline Pooled & 0.0002 & 0.79 & $<0.0001$ & $<0.0001$ & 0.026 & $<0.0001$ & $<0.0001$ & 0.0005 & 0.0021 & 0.71 \\
\hline MCI & 0.42 & 0.43 & $<0.0001$ & $<0.0001$ & 0.076 & $<0.0001$ & $<0.0001$ & 0.0049 & 0.0004 & 0.062 \\
\hline $\mathrm{AD}$ & 0.0002 & 0.46 & 0.0009 & 0.0012 & 0.22 & $<0.0001$ & 0.022 & 0.017 & 0.23 & 0.51 \\
\hline \multicolumn{11}{|l|}{ Education } \\
\hline Pooled & $<0.0001$ & 0.0012 & $<0.0001$ & 0.21 & 0.31 & 0.85 & 0.0061 & 0.77 & 0.21 & 0.64 \\
\hline MCI & 0.04 & 0.003 & 0.0091 & 0.52 & 0.74 & 0.62 & 0.12 & 0.44 & 0.56 & 0.45 \\
\hline $\mathrm{AD}$ & 0.0017 & 0.056 & 0.0032 & 0.03 & 0.15 & 0.93 & 0.025 & 0.51 & 0.12 & 0.88 \\
\hline \multicolumn{11}{|l|}{ Race } \\
\hline Pooled & 0.050 & 0.013 & $<0.0001$ & $<0.0001$ & 0.0007 & 0.0015 & 0.86 & 0.0077 & 0.15 & 0.86 \\
\hline MCI & 0.53 & 0.41 & $<0.0001$ & 0.0011 & 0.0002 & 0.0006 & 0.003 & $<0.0001$ & 0.13 & 0.12 \\
\hline $\mathrm{AD}$ & $<0.0001$ & $<0.0001$ & 0.10 & 0.20 & 0.78 & 0.99 & $<0.0001$ & 0.12 & 0.94 & 0.13 \\
\hline \multicolumn{11}{|l|}{ Married } \\
\hline Pooled & $<0.0001$ & 0.10 & $<0.0001$ & $<0.0001$ & 0.047 & $<0.0001$ & 0.0006 & 0.15 & 0.50 & 0.97 \\
\hline MCI & 0.0075 & 0.91 & 0.0088 & 0.015 & 0.42 & $<0.0001$ & 0.022 & 0.85 & 0.77 & 0.94 \\
\hline $\mathrm{AD}$ & $<0.0001$ & 0.010 & $<0.0001$ & 0.0021 & 0.26 & 0.0005 & 0.14 & 0.37 & 0.47 & 0.27 \\
\hline \multicolumn{11}{|c|}{ Parental history } \\
\hline Pooled & 0.011 & 0.19 & 0.07 & 0.18 & 0.43 & 0.0098 & 0.24 & 0.033 & 0.46 & 0.26 \\
\hline MCI & 0.45 & 0.64 & 0.8 & 0.98 & 0.99 & 0.012 & 0.45 & 0.5 & 0.79 & 0.12 \\
\hline $\mathrm{AD}$ & 0.045 & 0.36 & 0.019 & 0.17 & 0.39 & 0.23 & 0.46 & 0.069 & 0.21 & 0.99 \\
\hline \multicolumn{11}{|c|}{ Second-degree relative history } \\
\hline Pooled & 0.23 & 0.04 & 0.14 & 0.43 & 0.0502 & 0.17 & 0.79 & 0.0033 & 0.22 & 0.0031 \\
\hline MCI & 0.98 & 0.76 & 0.054 & 0.63 & 0.42 & 0.29 & 0.54 & 0.52 & 0.47 & 0.24 \\
\hline $\mathrm{AD}$ & 0.23 & 0.038 & 0.45 & 0.02 & 0.014 & 0.44 & 0.51 & 0.0037 & 0.10 & 0.014 \\
\hline \multicolumn{11}{|l|}{ MMSE } \\
\hline Pooled & $<0.0001$ & $<0.0001$ & 0.67 & $<0.0001$ & $<0.0001$ & 0.0019 & $<0.0001$ & $<0.0001$ & 0.014 & $<0.0001$ \\
\hline MCI & 0.055 & 0.29 & 0.28 & 0.005 & 0.87 & 0.087 & 0.42 & 0.8 & 0.52 & 0.42 \\
\hline $\mathrm{AD}$ & $<0.0001$ & 0.0041 & 0.25 & 0.54 & 0.86 & 0.056 & 0.09 & 0.87 & 0.55 & $<0.0001$ \\
\hline \multicolumn{11}{|l|}{ FAQ } \\
\hline Pooled & $<0.0001$ & $<0.0001$ & 0.06 & $<0.0001$ & $<0.0001$ & $<0.0001$ & $<0.0001$ & $<0.0001$ & $<0.0001$ & $<0.0001$ \\
\hline MCI & $<0.0001$ & $<0.0001$ & $<0.0001$ & $<0.0001$ & $<0.0001$ & $<0.0001$ & $<0.0001$ & $<0.0001$ & $<0.0002$ & $<0.0001$ \\
\hline $\mathrm{AD}$ & $<0.0001$ & $<0.0001$ & 0.25 & $<0.0001$ & $<0.0001$ & $<0.0001$ & $<0.0001$ & $<0.0001$ & $<0.0001$ & $<0.0001$ \\
\hline
\end{tabular}

p values in bold indicate significance. For the direction of the effect, please see 'Univariate Analyses' in the Results section. DEL = Delusions; HAL = hallucinations; DEP = depression; $\mathrm{APA}=$ apathy; $\mathrm{ANX}=$ anxiety; IRR = irritability; AGIT = agitation; DISN = disinhibition; ELAT = elation; MOT = aberrant motor behavior.

Functional impairment measured with the FAQ showed significant positive associations with the presence of all neuropsychiatric symptoms in all three samples except for depression where a positive association was observed only for MCI.

The univariate effects of race are best explained by associations with the factor variables. For all factor 1 variables, Caucasian race showed the highest, African American race the second highest and Asian race the lowest prevalence. This effect was significant for depression in the MCI and pooled samples, apathy in the pooled sample and anxiety in the MCI sample. Factor 2 distress/tension behaviors were significantly more common among African American compared to Asian subjects in all samples. Caucasians had the highest prevalence of irritability (i.e., higher than both African Americans and Asians) in the MCI and pooled samples and 
Apostolova et al.: Risk Factors for Behavioral Abnormalities in Mild Cognitive Impairment and Mild Alzheimer's Disease

of agitation in the MCI sample. Caucasians also showed the lowest prevalence of agitation in the mild AD sample. For factor 3 impulse control behaviors, the only significant associations were seen for disinhibition where we found that Caucasians had the highest and Asians the lowest prevalence among MCI subjects while at the same time in the AD sample Asians showed the highest and African Americans the lowest prevalence in the pooled sample. In both the $\mathrm{AD}$ and pooled samples, factor 4 psychotic behaviors were significantly more prevalent among African Americans followed by Asians and finally by Caucasians.

\section{Multivariable Analyses}

Multivariable analyses were restricted to subjects with all predictor data available $(2,786$ $\mathrm{MCI}$ and 2,075 mild $\mathrm{AD}$ ). 11 subjects (6 MCI and 5 mild $\mathrm{AD}$ ) had a missing race variable. 1,227 subjects (651 MCI and 576 mild AD) had a missing parental or second-degree relative history of dementia variable. Finally, 24 subjects (13 MCI and 11 mild AD) had a missing FAQ variable.

\section{Multivariable Logistic Regression Analyses}

Table 5 lists the odds ratios and confidence intervals for all significant predictors. Younger subjects showed significantly higher odds for having apathy, depression, anxiety, irritability and elation across all three samples, and higher odds for agitation and aberrant motor behavior in the MCI and pooled samples, and for disinhibition in the mild AD and pooled samples. The odds ratio for each additional year of age across all behaviors ranged between 0.96 and 0.99 .

Female gender was associated with higher odds for depression in the MCI and pooled sample (OR $=1.5$ and 1.33 , respectively), and anxiety in the MCI sample (OR $=1.28)$. Women had lower odds for irritability, apathy, and disinhibition in all three samples, for agitation and elation in the MCI and pooled samples and aberrant motor behavior in the MCI sample with odds ratios ranging from $\mathrm{OR}=0.3$ for elation among $\mathrm{MCI}$ subjects to $\mathrm{OR}=0.69$ for apathy in the mild AD sample (table 5).

Education influenced the odds for agitation in the pooled sample (OR $=0.98)$. Not being married was associated with higher odds for depression and delusions in all samples, and disinhibition and elation in the MCI sample only. The odds ratios ranged from $\mathrm{OR}=1.27$ for depression to $\mathrm{OR}=2.6$ for elation. Being married translated in greater odds for agitation in the mild AD sample (OR for not being married $=0.76$ ) (table 5 ).

Parental history of dementia was associated with higher odds for delusions (OR $=1.46)$ in mild $\mathrm{AD}$ and lower odds for depression in the mild $\mathrm{AD}$ and pooled samples (OR $=0.75$ and 0.85 , respectively). Second-degree relative history of dementia was associated with higher odds for hallucinations in the mild $\mathrm{AD}$ and pooled samples ( $\mathrm{OR}=1.86$ and 1.62 , respectively), as well as with decreased odds of elation in the AD sample (OR $=0.5)$ (table 5).

African American MCI subjects had lower odds for depression (OR $=0.51)$ and disinhibition $(\mathrm{OR}=0.27)$ than Caucasians. African American mild AD subjects had greater odds for agitation relative to Caucasians ( $\mathrm{OR}=2.27$ ). Asian $\mathrm{MCI}$ subjects showed lower odds for depression $(\mathrm{OR}=0.36)$, apathy $(\mathrm{OR}=0.25)$ and anxiety $(\mathrm{OR}=0.21)$ and higher odds for disinhibition $(\mathrm{OR}=$ 1.39) relative to Caucasians. Similar associations were seen in the pooled sample (table 4).

Subjects with greater functional impairment (higher FAQ) showed greater odds for the presence of all neuropsychiatric behaviors with the sole exception of depression in the mild $\mathrm{AD}$ and pooled samples (table 5).

\section{Univariate and Multivariable Analyses by MCI Subtype}

The univariate analyses included 2,837 amnestic and 619 nonamnestic MCI subjects. Agitation and elation were significantly more common among amnestic MCI subjects $(\mathrm{p}=$ 0.034 for both; table 2 ). 
Table 5. Logistic regression results - odds ratios ( $95 \% \mathrm{CI}$ ) of all significant predictors

\begin{tabular}{|c|c|c|c|c|c|c|}
\hline \multirow{4}{*}{$\begin{array}{l}\begin{array}{l}\text { Neuropsychiatric } \\
\text { behavior }\end{array} \\
\text { Delusions }\end{array}$} & \multicolumn{2}{|c|}{$\operatorname{MCI}(\mathrm{n}=2,779)$} & \multicolumn{2}{|c|}{ Mild AD $(n=2,075)$} & \multicolumn{2}{|c|}{ Pooled sample $(\mathrm{n}=4,854)$} \\
\hline & Not married & $1.78(1.1-2.85)$ & Parent & $1.46(1.09-1.94)$ & FAQ & $1.12(1.1-1.14)$ \\
\hline & FAQ & $1.15(1.11-1.19)$ & FAQ & $1.1(1.08-1.12)$ & Not married & $1.5(1.15-1.99)$ \\
\hline & & & Not married & 1.41 (1.01-1.99) & & \\
\hline \multirow[t]{2}{*}{ Hallucinations } & FAQ & $1.18(1.12-1.24)$ & 2nd degree & $1.86(1.05-3.32)$ & 2nd degree & $1.62(1.01-2.59)$ \\
\hline & & & FAQ & $1.07(1.03-1.11)$ & FAQ & $1.11(1.08-1.15)$ \\
\hline \multirow[t]{7}{*}{ Depression } & Age & $0.98(0.964-0.987)$ & Age & $0.98(0.96-0.99)$ & Age & $0.98(0.97-0.99)$ \\
\hline & Female & $1.5(1.22-1.85)$ & Other race & $1.83(0.91-3.66)$ & Female & $1.33(1.13-1.56)$ \\
\hline & Asian & $0.36(0.15-0.84)$ & Not married & $1.6(1.2-2.05)$ & Asian & $0.34(0.16-0.74)$ \\
\hline & $\mathrm{AA}$ & $0.51(0.38-0.69)$ & Parent & $0.73(0.58-0.92)$ & Other race & $1.80(1.21-2.69)$ \\
\hline & Other race & $1.6(0.98-2.67)$ & & & Not married & $1.40(1.18-1.65)$ \\
\hline & Not married & $1.27(1.03-1.58)$ & & & Parent & $0.85(0.73-0.99)$ \\
\hline & FAQ & $1.05(1.03-1.58)$ & & & & \\
\hline \multirow[t]{4}{*}{ Apathy } & Age & $0.98(0.967-0.992)$ & Age & $0.99(0.98-0.10)$ & Age & $0.98(0.98-0.992)$ \\
\hline & Female & $0.63(0.51-0.78)$ & Female & $0.69(0.56-0.85)$ & Female & $0.64(0.56-0.75)$ \\
\hline & Asian & $0.25(0.087-0.71)$ & MMSE & $1.05(1.01-1.09)$ & Asian & $0.43(0.23-0.81)$ \\
\hline & FAQ & $1.15(1.13-1.17)$ & FAQ & $1.07(1.06-1.09)$ & FAQ & $1.11(1.1-1.12)$ \\
\hline \multirow[t]{4}{*}{ Anxiety } & Age & $0.97(0.959-0.982)$ & Age & $0.97(0.96-0.98)$ & Age & $0.97(0.96-0.98)$ \\
\hline & Female & $1.28(1.04-1.57)$ & FAQ & $1.05(1.03-1.07)$ & Asian & $0.39(0.21-0.75)$ \\
\hline & Asian & $0.21(0.075-0.58)$ & & & FAQ & $1.067(1.057-1.079)$ \\
\hline & FAQ & $1.09(1.07-1.12)$ & & & & \\
\hline \multirow[t]{4}{*}{ Irritability } & Age & $0.97(0.959-0.98)$ & Age & $0.98(0.967-0.988)$ & Age & $0.97(0.966-0.98)$ \\
\hline & Female & $0.65(0.54-0.79)$ & Female & $0.67(0.55-0.83)$ & Female & $0.65(0.57-0.75)$ \\
\hline & FAQ & $1.11(1.09-1.13)$ & MMSE & $1.06(1.02-1.10)$ & MMSE & $1.05(1.03-1.08)$ \\
\hline & & & FAQ & $1.04(1.03-1.06)$ & FAQ & $1.07(1.06-1.08)$ \\
\hline \multirow[t]{5}{*}{ Agitation } & Age & $0.99(0.972-0.997)$ & AA & $2.27(1.64-3.12)$ & Age & $0.99(0.981-0.997)$ \\
\hline & Female & $0.6(0.48-0.75)$ & Not married & $0.76(0.6-0.98)$ & Female & $0.68(0.59-0.8)$ \\
\hline & FAQ & $1.12(1.09-1.14)$ & MMSE & $1.09(1.05-1.14)$ & Education & $0.98(0.96-0.1)$ \\
\hline & MMSE & $1.06(1.02-1.11)$ & FAQ & $1.06(1.04-1.07)$ & MMSE & $1.05(1.02-1.08)$ \\
\hline & & & & & FAQ & $1.09(1.07-1.1)$ \\
\hline \multirow[t]{5}{*}{ Disinhibition } & Female & $0.59(0.43-0.81)$ & Age & $0.98(0.97-0.10)$ & Age & $0.98(0.97-0.995)$ \\
\hline & Asian & $1.39(0.61-3.17)$ & Female & $0.65(0.5-0.86)$ & Female & $0.61(0.5-0.75)$ \\
\hline & $\mathrm{AA}$ & $0.27(0.14-0.52)$ & MMSE & $1.06(1.01-1.11)$ & Asian & $1.73(0.96-3.1)$ \\
\hline & Not married & $1.48(1.06-2.06)$ & FAQ & $1.08(1.06-1.1)$ & MMSE & $1.05(1.01-1.1)$ \\
\hline & FAQ & $1.15(1.12-1.17)$ & & & FAQ & $1.1(1.09-1.12)$ \\
\hline \multirow[t]{4}{*}{ Elation } & Age & $0.97(0.904-0.967)$ & Age & $0.97(0.94-0.1)$ & Age & $0.95(0.93-0.97)$ \\
\hline & Female & $0.3(0.15-0.61)$ & FAQ & $1.09(1.05-1.13)$ & Female & $0.48(0.32-0.74)$ \\
\hline & Not married & $2.6(1.3-5.0)$ & 2nd degree & $0.50(0.27-0.92)$ & FAQ & $1.1(1.07-1.13)$ \\
\hline & FAQ & $1.1(1.05-1.16)$ & & & & \\
\hline \multirow{3}{*}{$\begin{array}{l}\text { Aberrant motor } \\
\text { behavior }\end{array}$} & Age & $0.97(0.949-0.993)$ & FAQ & $1.1(1.08-1.13)$ & Age & $0.98(0.97-0.994)$ \\
\hline & Female & $0.63(0.41-0.96)$ & & & FAQ & $1.12(1.1-1.14)$ \\
\hline & FAQ & $1.14(1.1-1.17)$ & & & & \\
\hline
\end{tabular}

2nd degree $=$ Second-degree relative history of dementia; AA = African American; Parent = parental history of dementia. 
Dementia

and Geriatric

Cognitive Disorders

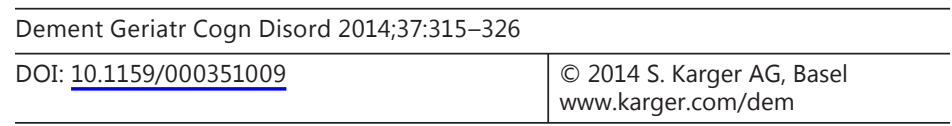

Apostolova et al:: Risk Factors for Behavioral Abnormalities in Mild Cognitive Impairment and Mild Alzheimer's Disease

Twenty MCI subjects were excluded from multivariate analyses due to missing data ( $\mathrm{n}=$ $3,436)$. We ran multivariable logistic regression models with elation and agitation as dependent variables and MCI subtype, age, gender, MMSE, FAQ and education - the 5 variables that were significantly different between the subtypes - as predictors. Amnestic MCI subjects showed significantly higher odds for the presence of elation $(\mathrm{OR}=3.03,95 \% \mathrm{CI}$ 1.08-8.53; $\mathrm{p}=0.036$ ) but not agitation after controlling for other variables. In addition to MCI subtype, the odds for elation was associated with younger age (OR $=0.95,95 \% \mathrm{CI} 0.93-0.98$; $\mathrm{p}=0.0016)$, male gender (OR $=2.7,95 \%$ CI 1.5-4.9; $\mathrm{p}=0.0007$ ) and higher FAQ scores (OR = $1.1,95 \%$ CI 1.06-1.15; p < 0.0001). Higher odds for agitation was associated with younger age $(\mathrm{OR}=0.99,95 \%$ CI $0.975-0.996 ; \mathrm{p}=0.0094)$, male gender $(\mathrm{OR}=1.76,95 \%$ CI $1.5-2.1$; $\mathrm{p}<0.0001)$ and worse FAQ scores (OR $=1.12$, 95\% CI 1.10-1.14; $<<0.0001)$.

\section{Discussion}

This is the largest study of behavioral symptoms in MCI and mild AD to date. The large sample size allowed us to conduct in-depth analyses of the risk factors associated with the prevalence of neuropsychiatric features among MCI and mild AD NACC participants. In our most conservative analyses after grouping NPI variables in 4 factors, we applied linear regression to investigate which demographic and cognitive variables show a significant association with each factor. The 4 factors identified were affective behaviors (depression, apathy and anxiety), distress/tension behaviors (irritability and agitation), impulse control behaviors (disinhibition, elation and aberrant motor behavior) and psychotic behaviors (delusions and hallucinations). We found that male gender was significantly associated with the presence of all 4 behavioral factors. Younger age was associated with a higher prevalence of distress/tension, impulse control and psychotic behaviors, while being married seemed protective against psychotic behaviors. Lower education was significantly related to the presence of distress/ tension behaviors. Caucasians were significantly more susceptible to affective behaviors.

Our findings agree with many observations reported in the literature. All analyses consistently demonstrated that disease severity measured by functional decline (FAQ) was the most powerful predictor for the presence of all behavioral abnormalities, which is consistent with previous reports [2]. The association of younger age with anxiety has previously been reported in $\mathrm{AD}$ in one Cache County study [7]. We confirmed this association in the MCI and pooled samples in both the univariate and multivariable logistic regression analyses.

Some of our findings disagree with previous reports. While Puccininni et al. [9] previously reported an association of older age and aberrant motor behaviors, we observed the opposite effect in the univariate and multivariable logistic regression analyses of the MCI and pooled samples. We were also unable to confirm the association between older age and psychosis reported by two previous studies $[8,9]$ and found the opposite association across all three samples in the univariate but not the multivariable analyses.

Our findings with respect to education extend previous reports. Three studies [10-12] reported a negative association between education and prevalence of depression in AD. Others reported lack of association or an association in the opposite direction [13-15]. We observed a negative association between education and prevalence of depression in all samples in the univariate analyses that disappeared once we corrected for multiple comparisons.

In terms of family history of dementia, our univariate and multivariable logistic regression findings agree with those of Jost and Grossberg [16] and Sweet et al. [20] who reported a higher prevalence of anxiety, irritability and psychosis among AD subjects with a positive family history. 
Dementia

Cognitive Disorders

\begin{tabular}{l|l}
\hline \multicolumn{2}{l|}{ Dement Geriatr Cogn Disord 2014;37:315-326 } \\
\hline DOI: $\underline{10.1159 / 000351009}$ & $\begin{array}{l}\text { (c) 2014 S. Karger AG, Basel } \\
\text { www.karger.com/dem }\end{array}$ \\
\hline
\end{tabular}

Apostolova et al.: Risk Factors for Behavioral Abnormalities in Mild Cognitive Impairment and Mild Alzheimer's Disease

Our findings are also in agreement with the reported association from the Cache County study of females with AD having a higher prevalence of anxiety [7].

With regard to the prevalence of neuropsychiatric symptoms among MCI subtypes, our findings disagree with previous reports. We failed to see a higher prevalence of apathy among amnestic MCI and of hallucinations among nonamnestic MCI subjects as previously reported $[21,22]$. We somewhat surprisingly uncovered a higher prevalence of elation (univariate and multivariable analyses) and agitation (univariate analyses) among amnestic compared to nonamnestic MCI subjects.

In addition, our multivariable logistic regression analyses showed many previously unrecognized associations. We found that younger age associates with a higher prevalence of depression, elation and irritability in all three samples, with agitation, apathy and aberrant motor behavior in MCI and the pooled sample and with disinhibition in the pooled sample in the multivariable logistic regression analyses. Female gender was largely protective against NPI symptoms with the exception of depression and anxiety. Married MCI subjects were less likely to have depression, delusions, elation and disinhibition. Married mild AD subjects had less depression and agitation.

Several strengths and weaknesses of our study need to be recognized. Due to its large sample size, our paper is the first one to report several important observations with respect to NPI symptom prevalence. Those that stand out are the overall higher prevalence of behavioral abnormalities in younger subjects, males and those with more significant functional impairment. The weaknesses of our study are the fact that several putative risk factors - especially those associated with cognitive reserve such as occupational attainment, socioeconomic status and social and leisure activities - were not available in the NACC and limited our ability to study the presence of behavioral reserve in MCI and mild AD. Given the lack of a strong association between education and lower prevalence of NPI symptoms, we must conclude that we find no evidence of behavioral reserve in $\mathrm{MCI}$ and mild $\mathrm{AD}$ although this might very well be a premature conclusion in view of the lacking data points to exhaust this question. Other more thorough data sets might offer a better opportunity to firmly establish the absence or presence of behavioral reserve. An additional limitation of the study is the fact that the data are collected at tertiary health care centers with federally funded Alzheimer's disease research programs. Such environments are well known to attract highly educated, predominantly Caucasian subjects. The fact that we report many associations in non-Caucasian participants is however reassuring that we have at least some statistical power to make such observations. NACC data are being collected at more than 30 sites - the NIH-funded Alzheimer's Disease Research Centers. These centers are spread across the United States. As such, NACC data do not suffer from a significant geographical bias. They do however suffer from a sampling bias as they represent a collection of multiple convenience samples. Patients seen at Alzheimer's Disease Research Centers are typically highly educated, predominantly white and many have a positive family history of AD (table 1). Hence the NACC cohort is not an accurate representation of the elderly population in the USA. Despite the fact that we have in our multivariable analyses adjusted for age, race and dementia family history, our study findings should be generalized with caution.

In summary, our comprehensive analysis of the social and demographic factors that influence behavioral symptom prevalence revealed that younger subjects, Caucasian subjects, men, subjects with lower education and subjects with greater functional impairment have a higher overall presence of behavioral abnormalities in MCI and mild AD. Marital status, lower education and race had an effect on the prevalence of selected behaviors only. Following this comprehensive investigation, our next step will be to study the risk factors associated with the emergence (i.e., incidence) of neuropsychiatric behaviors across the spectrum from normal aging to $\mathrm{AD}$. 
Apostolova et al.: Risk Factors for Behavioral Abnormalities in Mild Cognitive Impairment and Mild Alzheimer's Disease

\section{Acknowledgments}

This work was supported by NACC Junior Investigator Project (U01 AG016976), NIA P50 AG16570.

\section{Disclosure Statement}

Liana G. Apostolova serves on the speaker bureau for Eli Lilly Pharmaceuticals and has received research support from NIA R01 AG040770, NIA P50 AG16570, NIA U01 AG02490, NIA K23 AG026803 jointly sponsored by NIA, AFAR, The John A. Hartford Foundation, the Atlantic Philanthropies, the Starr Foundation and an anonymous donor, and the Easton Consortium for Alzheimer's Drug Discovery and Biomarker Development. Dr. Apostolova serves as a consultant for Griffols.

Li Jie Di reports no disclosures.

Erin L. Duffy reports no disclosures.

Jenny Brook reports no disclosures.

David Elashoff has received research support from NIA P50 AG16570, UL1 RR033176, U01 CA15251, K01 EB013633, R01 AG040770, U01 DE017593, P30 CA16042, R01 CA126944, P50 CA092131, U01 DA023815, R01 CA123055 and R21 AR057913.

Chi-Hong Tseng reports no disclosures.

Lynn Fairbanks reports no disclosures.

Jeffrey L. Cummings owns the copyright to the Neuropsychiatric Inventory. Dr. Cummings has provided consultation to Abbott, ADAMAS, Anavex, Avanir, Baxter, Bristol-Myers Squibb, Eisai, Elan, EnVivo, Genentech, GE, GlaxoSmithKline, Griffols, Lilly, Lundbeck, MedAvante, Merck, Novartis, Otsuka, Pfizer, Prana, QR Pharma, Sonexa, Suven, Takeda pharmaceutical companies. Dr. Cummings owns stock in ADAMAS, Prana, Sonexa, MedAvante, Neurotrax, and Neurokos. Dr. Cummings has provided expert witness consultation regarding olanzapine and ropinerol.

\section{References}

- 1 Mega MS, Cummings JL, Fiorello T, Gornbein J: The spectrum of behavioral changes in Alzheimer's disease. Neurology 1996;46:130-135.

2 Apostolova LG, Cummings JL: Neuropsychiatric manifestations in mild cognitive impairment: a systematic review of the literature. Dement Geriatr Cogn Disord 2008;25:115-126.

- 3 Scarmeas N, Brandt J, Albert M, et al: Delusions and hallucinations are associated with worse outcome in Alzheimer disease. Arch Neurol 2005;62:1601-1608.

4 Lam LC, Tam CW, Chiu HF, Lui VW: Depression and apathy affect functioning in community active subjects with questionable dementia and mild Alzheimer's disease. Int J Geriatr Psychiatry 2007;22:431-437.

- 5 Teri L: Behavior and caregiver burden: behavioral problems in patients with Alzheimer disease and its association with caregiver distress. Alzheimer Dis Assoc Disord 1997;11(suppl 4):S35-S38.

6 Gilley DW, Bienias JL, Wilson RS, Bennett DA, Beck TL, Evans DA: Influence of behavioral symptoms on rates of institutionalization for persons with Alzheimer's disease. Psychol Med 2004;34:1129-1135.

7 Steinberg M, Corcoran C, Tschanz JT, et al: Risk factors for neuropsychiatric symptoms in dementia: the Cache County Study. Int J Geriatr Psychiatry 2006;21:824-830.

8 Bassiony MM, Steinberg MS, Warren A, Rosenblatt A, Baker AS, Lyketsos CG: Delusions and hallucinations in Alzheimer's disease: prevalence and clinical correlates. Int J Geriatr Psychiatry 2000;15:99-107.

- 9 Piccininni M, Di Carlo A, Baldereschi M, Zaccara G, Inzitari D: Behavioral and psychological symptoms in Alzheimer's disease: frequency and relationship with duration and severity of the disease. Dement Geriatr Cogn Disord 2005;19:276-281.

10 Lobo A, Saz P, Marcos G, Dia JL, De-la-Camara C: The prevalence of dementia and depression in the elderly community in a southern European population. The Zaragoza study. Arch Gen Psychiatry 1995;52:497-506.

11 Gabryelewicz T, Religa D, Styczynska M, et al: Behavioural pathology in Alzheimer's disease with special reference to apolipoprotein E genotype. Dement Geriatr Cogn Disord 2002;14:208-212.

$>12$ Devanand DP, Miller L, Richards M, et al: The Columbia University Scale for Psychopathology in Alzheimer's disease. Arch Neurol 1992;49:371-376.

-13 Geerlings MI, Schmand B, Braam AW, Jonker C, Bouter LM, van Tilburg W: Depressive symptoms and risk of Alzheimer's disease in more highly educated older people. J Am Geriatr Soc 2000;48:1092-1097.

14 Binetti G, Bianchetti A, Padovani A, Lenzi G, De Leo D, Trabucchi M: Delusions in Alzheimer's disease and multiinfarct dementia. Acta Neurol Scand 1993;88:5-9. 
$>15$ Gilley DW, Wilson RS, Bennett DA, Bernard BA, Fox JH: Predictors of behavioral disturbance in Alzheimer's disease. J Gerontol 1991;46:P362-P371.

16 Jost BC, Grossberg GT: The evolution of psychiatric symptoms in Alzheimer's disease: a natural history study. J Am Geriatr Soc 1996;44:1078-1081.

17 Sweet RA, Nimgaonkar VL, Devlin B, Lopez OL, DeKosky ST: Increased familial risk of the psychotic phenotype of Alzheimer disease. Neurology 2002;58:907-911.

18 Petersen RC, Doody R, Kurz A, et al: Current concepts in mild cognitive impairment. Arch Neurol 2001;58: 1985-1992.

19 McKhann G, Drachman D, Folstein M, Katzman R, Price D, Stadlan EM: Clinical diagnosis of Alzheimer's disease: report of the NINCDS-ADRDA Work Group under the auspices of Department of Health and Human Services Task Force on Alzheimer's Disease. Neurology 1984;34:939-944.

20 Sweet RA, Hamilton RL, Lopez OL, et al: Psychotic symptoms in Alzheimer's disease are not associated with more severe neuropathologic features. Int Psychogeriatr 2000;12:547-558.

21 Ellison JM, Harper DG, Berlow Y, Zeranski L: Beyond the 'C' in MCI: noncognitive symptoms in amnestic and non-amnestic mild cognitive impairment. CNS Spectr 2008;13:66-72.

-22 Rozzini L, Vicini Chilovi B, Conti M, et al: Neuropsychiatric symptoms in amnestic and nonamnestic mild cognitive impairment. Dement Geriatr Cogn Disord 2008;25:32-36. 